\title{
Design for Novel Appearance of Mini Electric Car
}

\author{
Zhongyao $\mathrm{Wu}^{\mathrm{a}}$, Jianbo $\mathrm{Cao}^{\mathrm{b}}$, Qifen $\mathrm{Gu}^{\mathrm{a}}$, and Tianfeng Zhao ${ }^{\mathrm{a}}$ \\ College of Engineering, Zhejiang Normal University, Jinhua, Zhejiang 321004, P. R. China

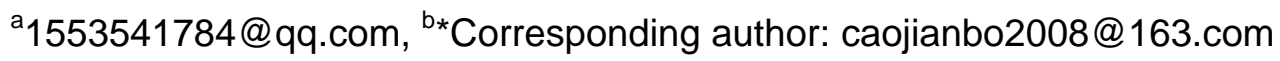

Keywords: Electric car, Finite element, Appearance design, UG

\begin{abstract}
With the rapid development of global environment protection, the development of electric car has been more popular as well as the appearance design of electric car has been given an extensive research. A novel appearance of mini electric car was designed by studying the basic theory and method of electric car appearance design. The finite element analysis and dynamic analysis of specific parts of the mini electric car body was also done by using UG software making plain design and 3D modeling in order to optimize the bodywork design and make the mini electric car practical.
\end{abstract}

\section{Introduction}

The limited petroleum resources are reserved less and less and it caused environmental pollution more and more serious, especially the global energy shortage and environment pollutions while it is used as human major source of energy at the present time. It is not only related to the world economic growth, but also the human' subsistence and development, and even it would involve the living condition of every human being on the earth. Faced with this severe situation, the governments are all seeking the solution. The governments and automobile industries all have realized that electric car is keeping stay abreast of the world trend in the course of exploration and also closely relating with the national conditions. It could protect the environment to a certain extent and reduce the problem of energy shortage [1-2].

During the electric car development process, the body appearance design is the noticeable link of the process. Body appearance design includes the designs of all items of the body, and its general idea aims at good appearance, high performance function, good aerodynamic characteristics, easy to manufacture, simple to assemble and disassemble on the premise of achieve corresponding functions. Using computer technology as a means is the prominent feature of the modern body design. For the computer technology, there are some popular softwares, SOLIDWORKS, UG, PRO/E, CATIA, which are used for modeling, ANSYS for Finite element analysis and the ADAMS for motion simulation. In addition, 3D MAX is good at modeling and could achieve product promotion [3-9]. In this paper the author designed a kind of practical novel appearance of mini electric car with the plaindesign and 3Dmodeling by using the UG software, and the finite element analysis and dynamic analysis.

\section{Body Appearance Design}

Before the mini electric car body design, it needs to acquire elementary structural information of the car on the whole. It does not need every subsystem to be optimalizing according to the features of the mini electric car. The design of the mini electric car is mainly divided into three parts: storage device, body and undercarriage system, drive and control system.

As for the car body and structure, body shell is made by many big covers with space curved face (such as roof, fender and engine hood, etc). As for shape on the whole, it should be streamlined to reduce the air resistance, and give people good impressions at the same time. And the size and height of it should be reasonable and suitable. In this paper the author described a mini electric car's body appearance sketch based on the available mini car, customized the general size, and drew the 3D model through the UG. UG is a functional 3D design software and plays an important role in appearance design with being used for modifying the size, matching colors, rendering environment, 
and working out the mini electric car's final painting. In this paper the body appearance of miniature electric car is shown as Fig. 1 to Fig. 4.

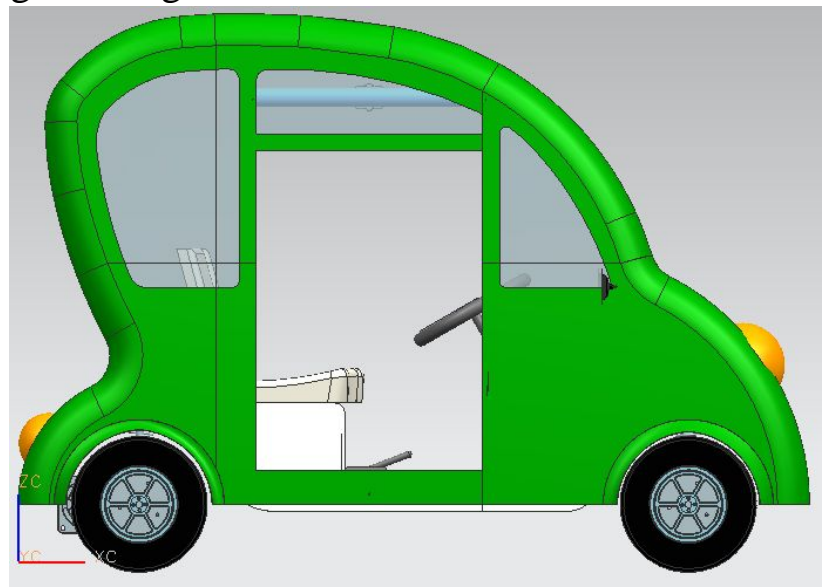

Fig. 1 The orthograph of mini electric car

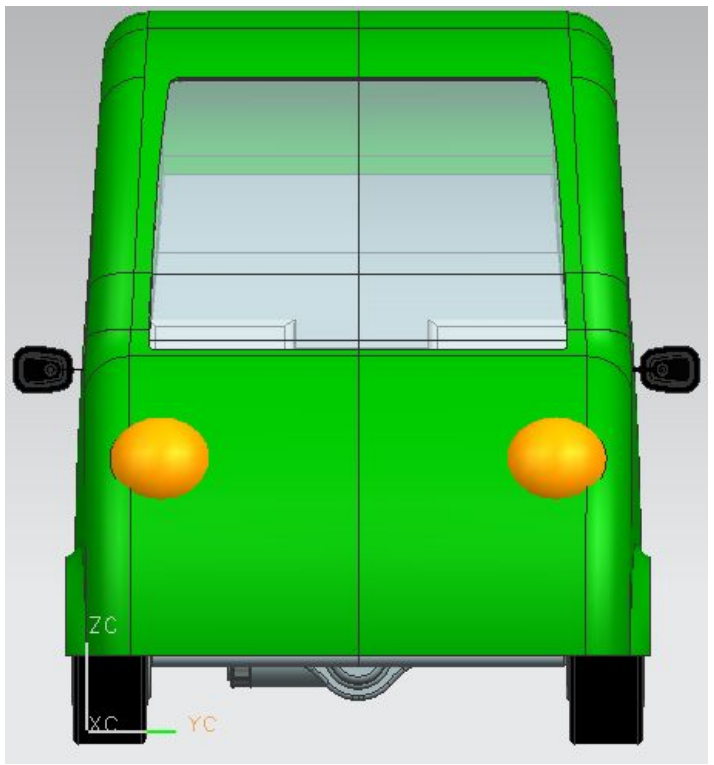

Fig. 2 The front view of mini electric car

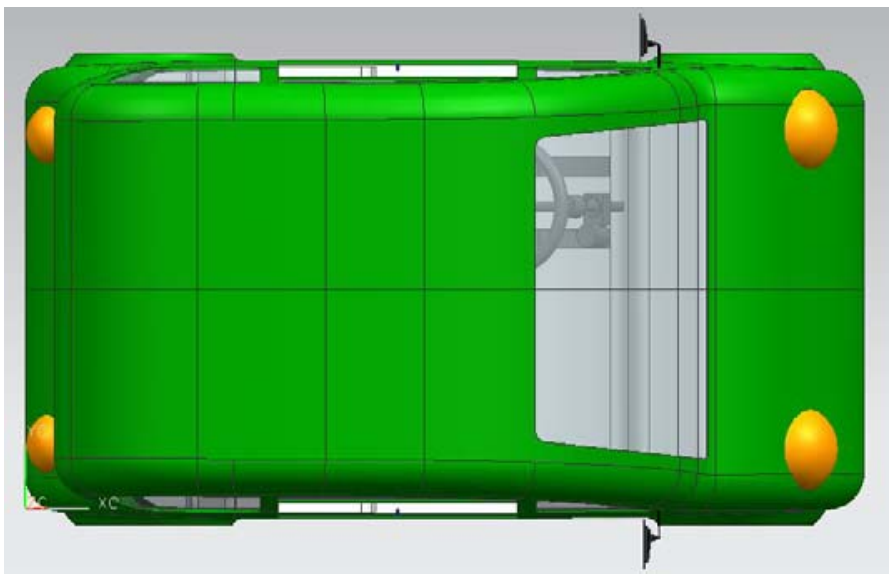

Fig. 3 The top view of mini electric car 


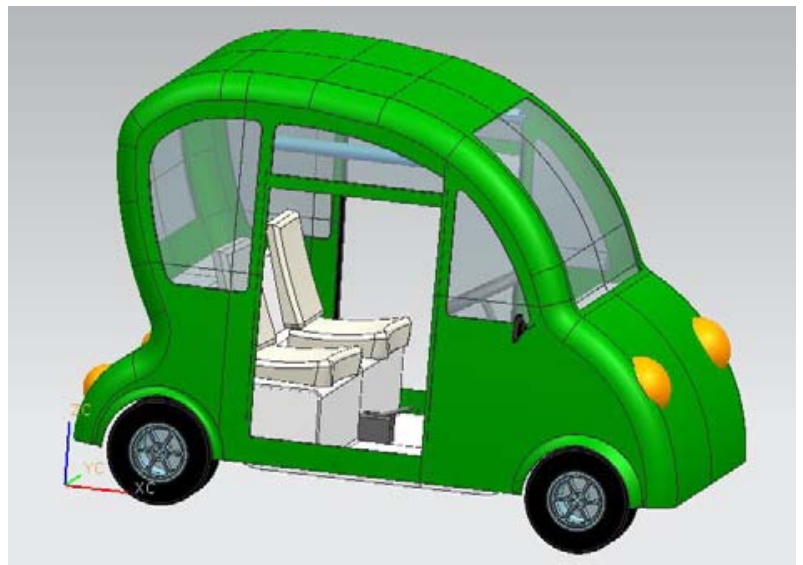

Fig. 4 The three-dimensional spatial pattern of mini electric car

\section{The Finite Element Analysis of Car Body}

Having referenced to those mini electric car body materials both at home and abroad, in this paper the author chose GRP as the main material of the car body. GRP, also named GFRP, takes synthetic resin viny lite as adhesives and synthesize fiber glass and products of fiber glass as reinforce material. The most distinct mechanical properties of GRP is lightweight and high intensity. Its density is $1.5 \sim 2.0 \mathrm{~kg} / \mathrm{m} 3$, only $1 / 4$ to $1 / 5$ of the steel, smaller than the aluminum (2.7 kg/m3). In addition, GRP has many good characteristics, such as the anti-fatigue performance, vibration damping, chemical and moisture resistant, good electrical insulating properties, thermal excellent performance and good workability. It has been widely used in many fields, such as the car, ship, railway transportation, construction, daily necessities, furniture, electrical and mechanical equipment, chemical, oil, national defense and so on.

There are dozens of kinds of molding technology of the GRP, according to the technical principle mainly including: hand paste molding, injection molding, winding forming, filament winding, compression molding forming, reaction injection molding, pultrusion molding, etc. In this paper the solar electric car body uses the molding paste hand.

Hand paste forming technology is a no pressure or low pressure molding technology taking room temperature curing heat curing resins, such as unsaturated polyester, epoxy resin ,to bond together with glass fiber and its fabric and some reinforcing materials. This technology occupies a major position in China in GRP industrial manufacturing. The main raw material of the molding paste hand are reinforcer (twist throwing, slight twist, chopped strand matting, surface mat, etc.), synthetic resin (unsaturated polyester, epoxy resin, etc.), curing agent (peroxide curing agent, amine, etc.), promoting agent, fillers, coloring agent, flame retardant, antistatic agent, etc.

At present, followed by the market, various types of application softwares have appeared, including some powerful CAE softwares, such as NASTRAN, ADINA, ANSYS, ABAQUS, MARC, MAGSOFT, COSMOS, and have widely used as a very powerful tool to solve complex theoretical calculation. However, every software has its own advantage and so its application field is very different from others. And then the body finite element analysis is mainly composed of UG software because the design of three dimensional model is made by UG software, and UG software owns the function of the finite element analysis. Fig. 5 is body displacement-Node Finite Element analysis. Fig. 6 is body strain-element node finite element analysis. According to the simulation results, in this paper the electric motor car body shape displacement and strain is very small, but meets the requirements of practical application in the permitted range.

\section{Conclusion}

In this paper, the designed items come with the environmental protection all over the world. The development of electric cars is popular and wins people's supports under the global environment 
protection. Mini electric car research also has deserved the attention of all the governments. In this paper the author aims at the research of mini electric car body, such as the whole body shape design being simple, costing little, being convenient and practical, and using UG software to make finite element analysis for miniature electric car 3D model of the main parts, so as to ensure the strength of the mini electric car and prevent the potential safety hazard. The results show that the design is accord to principle and it builds foundation for the future body design of this mini electric car.

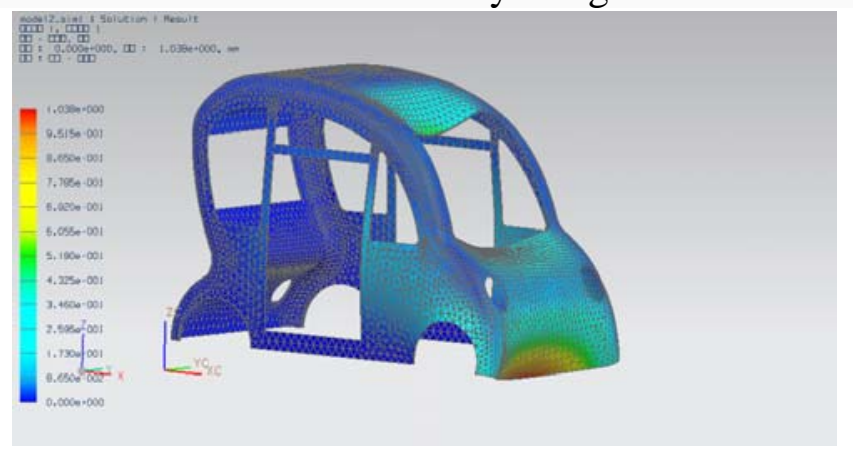

Fig. 5 Displacement-node analysis

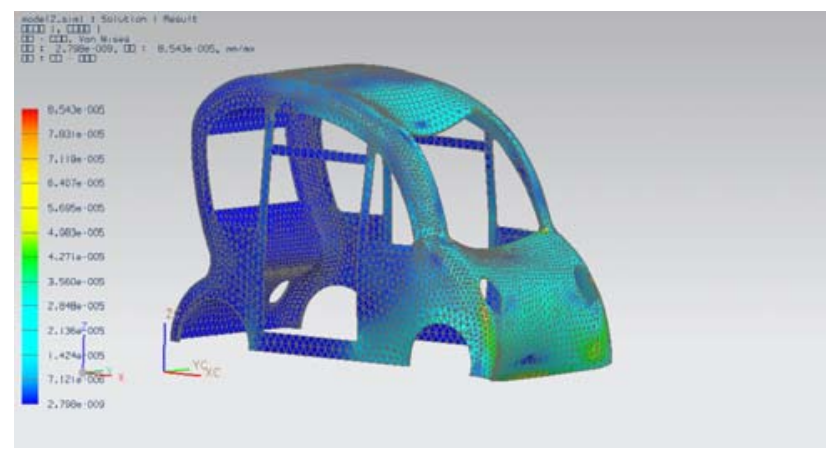

Fig. 6 Strain-element node analysis

\section{Acknowledgement}

The work was Supported by the Key Project of Chinese Ministry of Education (No. 211071), the Science and Technology Project of Jinhua City (No. 2010-1-101), and the Key Research Project of Education Department of Zhejiang Province (No. Z201018813).

\section{References}

[1] G.M. Wang and J.Y. Wang: Automobile Industry Research, (2008) No. 11, pp. 2-6.

[2] Y. Ma: Chinese Invention and Patent, (2006) No. 6, pp. 86-88.

[3] Y.F. Fu, D.F. Jin and W.W. Qiao: Journal of Mechanical Engineering, Vol. 45 (2009) No. 9, pp. 210-213.

[4] Y.G. Gao, F. Jiang, X. Jiang and X.B. Chen: Chinese Mechanical Engineering, Vol. 17 (2006), pp. 404-407.

[5] R. Ren: Journal of Zhejiang Normal University (Social Sciences), (1991) No. 4, pp. 73-78.

[6] W.W. Qiao, D.F. Jin and X.L. Yu: Tianjin Automobile, (2008) No. 8, pp. 36-43.

[7] M.W. Suh and W.H. Yang: Journal of Mechanical Science and Technology, Vol. 15 (2001) No. 12, pp. 1639-1646.

[8] M.R. Signori and R. Garcia: IFMBE Proceedings, Vol. 25 (2009) No. 7, pp. 449-452.

[9] C.J. Higgins, H.S. Matthews, C.T. Hendrickson and M.J. Small: Transportation Research Part D 12, (2007), pp. 103-114. 